\title{
Desvendando os Males do Sertão Goiano por Meio da História da Saúde e das Doenças
}

\author{
MAGALHÃES, Sônia Maria. Males do Sertão: Alimentação, saúde e \\ doenças em Goiás no século XIX. Goiânia: Cânone Editorial, 2014.
}

\section{Resenha}

A relevância do papel da alimentação no surgimento de doenças na província de Goiás no século XIX é o principal objetivo de Sônia Maria de Magalhães ${ }^{1} \mathrm{em}_{\text {Males }}$ do Sertão: Alimentação, saúde e doenças em Goiás no século XIX, cujo livro é resultado de sua tese de doutorado defendida na Universidade Estadual Paulista "Júlio de Mesquita Filho", campus de Franca, em 2004.

A autora busca evidenciar que o cotidiano da população goiana não passou por mudanças significativas na passagem do século XVIII para o XIX. Em uma narrativa convidativa à leitura, surge um panorama social, econômico e epidemiológico de Goiás durante o século XIX. O livro se compõe em três partes: "O problema alimentar e as doenças reinantes no Brasil", "Alimentação e enfermidades em Goiás" e "Assistentes, saúde e agentes a serviço da cura”.

Na introdução, Magalhães elucida que seu objetivo é esclarecer a forma pela qual as possibilidades alimentares influenciaram no advento de diversas moléstias entre a população goiana, com destaque para a grande quantidade de pessoas com doenças mentais. A fome constituía-se como um grande problema, que por sua vez encontrava-se relacionado à crise de abastecimento, sendo este agravado pela constante alternância entre os períodos de seca e inundações no território goiano. As contínuas crises de fome e carestia de alimentos determinaram as possibilidades e, por conseguinte, as preferencias alimentares da população goiana, cuja alimentação se baseava no consumo de farinha de milho e de mandioca, acompanhada de carne-seca, quando era possível, e frutos silvestres provenientes do cerrado.

\footnotetext{
${ }^{1}$ Professora do Programa de Pós-Graduação e da Faculdade de História da Universidade Federal de Goiás. Atualmente é coordenadora do GT História da Saúde e das doenças/ANPUH - Seção Goiás.
} 
Magalhães situa historicamente o seu objeto de estudo desde os primórdios da colonização do território brasileiro até início do século XX em um contexto que não se sabia a causa e a etiologia das doenças. Com isso, a autora faz uma investigação comparativa entre diferentes fontes, que são compostas pelos discursos dos viajantes estrangeiros, como relatórios médicos, diários de dietas, quadros de fluxos econômicos e comerciais, mapas, registros de óbitos, prontuários, relatórios oficiais de presidentes de província, tabelas com as moléstias incidentes, etc. Assim, elucida aspectos pouco conhecidos sobre a saúde da população goiana no século XIX.

A obra revela de forma evidente os Males do Sertão, que são compostos mediante a multiplicidade de doenças em virtude da alimentação corriqueira e insuficiente, ausência de uma política assistencial ligada à saúde e o desamparo da população diante o governo. Compondo deste modo, uma valiosa analise sobre a qual as moléstias não são vistas isoladamente dos problemas de ordem socioeconômica, política e cultural.

Entre as contribuições do estudo destacam-se: o panorama econômico de Goiás no século XIX, a sistematização das principais doenças, as moléstias reinantes na província, o exercício médico e as práticas curativas apregoadas no período, à relação da atividade pecuária voltada para a produção externa e a escassez do consumo entre a população local.

Magalhães, também trabalha a carência de médicos na província de Goiás e o uso de métodos alternativos diante da escassez de profissionais formados. Sendo assim, em terras sem médicos e nem cirurgiões formados, as intervenções eram realizadas por curiosos ou por aqueles que se aventuravam a cuidar da saúde alheia. Tais práticas se compunham na figura das parteiras, boticários, farmacêuticos, barbeiros, cirurgiões, benzedores, feiticeiros, entre outros. ${ }^{2}$

Tomando como referência a escala social das profissões, os médicos detinham uma importância capital e, por exercerem atividades consideradas de outra natureza, seguiam os cirurgiões e por último os barbeiros de forma classificatória. Dessa forma, ainda no Brasil colonial, a divisão tradicional baseava-se entre os seguintes profissionais: o médico, o cirurgião e o boticário. Cada qual com a sua função, uma vez que, aos

\footnotetext{
${ }^{2}$ Os cirurgiões eram práticos que exerciam a função de médicos devido à ausência de profissionais formados. Os barbeiros ou sangradores compreendiam os práticos que ofereciam o serviço de barba e corte de cabelo e também a aplicação de ventosas e sanguessugas no corpo do indivíduo doente. Com relação aos boticários, estes geralmente eram donos de boticas, cuja função estava restrita ao preparo e manipulação de substancias e suas propriedades. Já os demais indivíduos que se aventuravam a exercer o ofício médico sem possuir formação acadêmica, a exemplo das parteiras, eram denominados de "práticos da medicina".
} 
médicos caberia medicar, aos cirurgiões, intervir no corpo doente e aos boticários manipular os medicamentos. Vale ressaltar que as intervenções cirúrgicas, eram realizadas sem anestesia, transformando o ato cirúrgico em uma verdadeira barbárie.

Todavia, do fim do século XIX até o início do século XX, a medicina brasileira não desfrutava do mesmo prestigio social que possui na atualidade enquanto profissão. Sendo assim, até o início da modernidade, os médicos desconheciam o corpo humano internamente. De modo que, tanto o diagnostico quanto o tratamento eram basicamente empíricos. Assim, no respectivo período a medicina provavelmente matava tanto quanto curava, situação que começou a ser mudada com a revolução cientifica no fim do século $\mathrm{XIX}^{3}$.

No decorrer do século XIX, nota-se um movimento que buscou definir os espaços ocupados pelos indivíduos que atuavam na cura. O processo de institucionalização da medicina como atividade diversa da então praticada por barbeiros, sangradores e práticos, determinou a fundação da Sociedade de Medicina no ano de 1829. De modo que, se nota uma luta cada vez mais acentuada por parte das autoridades para inibir a atuação daqueles indivíduos que não possuíam uma formação acadêmica, considerados como charlatões.

A segunda parte do livro é composta por uma rica sistematização de dados sobre as doenças reinantes em Goiás no século XIX, com base nas observações dos viajantes estrangeiros e nos registros de óbitos emitidos pelo Hospital de Caridade São Pedro de Alcântara.

Através da literatura produzida pelos viajantes estrangeiros e médicos, encontramos aspectos ricos sobre o cotidiano alimentar da população goiana, uma vez que se compõem como um manancial de informações e permitem inúmeras leituras. $\mathrm{Na}$ medida em que se adentrava no interior do território, o viajante Johann Baptist Emanuel $\mathrm{Pohl}^{4}$ relatou sobre as dificuldades de se adquirir os alimentos mais necessários como, toucinho, feijão e farinha de milho.

De acordo com Sônia, pouco se sabe sobre a composição das refeições nas casas mais abastadas. No entanto, é notório que o mal mais temido diante da fome era ter as

\footnotetext{
${ }^{3}$ A Revolução Científica corresponde a uma série de fatores e mudanças que desencadearam o advento das ciências modernas. De modo que, se buscou repensar inúmeros campos do saber como a biologia, a medicina e anatomia. Assim, em fins do século XIX, as descobertas dos cientistas e médicos, promoveram uma revolução no campo da prática médica, elevando assim, a medicina para o campo da cientificidade. ${ }^{4}$ Médico, geólogo e botânico austríaco. Nasceu em Kanitz, na Boêmia no ano 1782. Dedicou uma singular paixão à botânica, tornando-se professor desta disciplina na Universidade de Praga. Integrou a Missão Austríaca ao Brasil entre os anos de 1817 e 1822, por meio da qual, produziu um diário de viagem intitulado Viagem no interior do Brasil; empreendida nos anos de 1817 a 1821, cuja publicação ocorreu na cidade do Rio de Janeiro no ano de 1951.
} 
despensas vazias a ponto de não ter a possibilidade de oferecer nada aos visitantes. Assim, conclui-se que o papel simbólico e social do alimento parece ser mais relevante do que a sua função nutritiva.

No que tange o cenário nosológico ${ }^{5}$, o território goiano apresentava uma situação sanitária ambígua, uma vez que era descrito simultaneamente como saudável e insalubre. De modo que, a diversidade ambiental entre as comarcas Norte e Sul do território possibilitou classificações duvidosas.

Magalhães aprofunda a sua análise por meio dos registros de óbito do Hospital de Caridade São Pedro de Alcântara no contexto em que é inaugurado o cemitério público no ano de 1859. Momento sobre o qual, os enterros e serviços fúnebres passaram a ser de responsabilidade do sanatório público.

A partir disso e por meio dos relatórios de óbitos, a autora constatou que a fase mais crítica da população situava-se nos dez primeiros anos de vida e de acordo com os registros, a maioria das mortes ocorria antes ou depois do parto. Assim, por mais que os óbitos não possam relevar o real impacto das doenças nutricionais entre as crianças, oferecem pistas evidentes sobre os efeitos da fome em Goiás. Vale ressaltar que no decorrer da gestação e após o parto, as crianças eram prejudicadas pelo mal estado nutricional de suas mães, que sofriam com a falta de cálcio, vitamina D e beribéri.

A terceira e última parte, abarca a assistência à saúde e as práticas de cura. Sônia trabalhou a importância do Hospital de Caridade São Pedro de Alcântara no processo de assistência aos enfermos pobres e indigentes. Sendo assim, o Hospital prestava amparo material e espiritual à comunidade, tanto na vida como na morte. No Brasil, a saúde pública fora colocada em segundo plano, sendo vislumbrada como uma questão de caridade publica, visto que não era tida como uma obrigação do governo. Assim, cabia a cada morador individualmente o cuidado e a responsabilidade com as questões sanitárias.

No entanto, não havia uma cultura médica no Brasil, assim a população não tinha o costume de realizar consultas e muitos consideravam o ambiente hospitalar como um local destinado à morte. Visto que diversas pessoas só recorriam ao Hospital em último caso, quando já não lhe restava outra opção senão a morte. “A falta de camas e de espaço, as péssimas condições, a inadequada localização das enfermarias e os parcos recursos contribuíram de alguma forma para o aumento da mortalidade nas dependências do hospital chegando a atingir 36,8\% no ano de 1880" (MAGALHÃES, 2014:158).

\footnotetext{
${ }^{5} \mathrm{O}$ cenário nosológico compreende o estudo das moléstias reinantes.
} 
Além disso, o uso de elementos naturais, como plantas medicinais nativas, possibilitou a construção do maior arsenal terapêutico utilizado na cidade de Goiás, uma vez que a dificuldade de acesso aos produtos europeus influenciou no aproveitamento dos medicamentos da flora medicinal brasileira. Os médicos seguidores da teoria de Galeno - que defendia a composição do corpo humano em quatro humores, sendo eles: bílis negra, bílis amarela, sangue e a fleuma - se preocupavam com os efeitos das estações do ano e das águas sobre o indivíduo e a ação dos ventos sobre a saúde. Vale ressaltar que a medicina dos humores vigorou na mentalidade dos brasileiros ao longo do Oitocentos.

Com relação às dietas, estas eram prescritas pelo médico e deveriam permanecer fixadas a cabeceira do leito do enfermo, junto com as respectivas orientações. Assim, os horários das refeições, eram controlados rigorosamente por um clínico, uma vez que eram tão importantes quanto à quantidade de comida prescrita ao doente.

Para além de discutir o processo de institucionalização da medicina em Goiás, a obra em questão busca examinar três médicos que se estabeleceram e construíram suas carreiras profissionais em Goiás, sendo eles: Vicente Moretti Foggia ${ }^{6}$, Theodoro Rodrigo de Moraes $^{7}$ e Francisco Antônio de Azeredo $^{8}$. Para os três doutores, o exercício da medicina na cidade de Goiás se processou de forma pausada, já que tinham que competir com a figura dos práticos que serviam os habitantes locais que requisitavam seus serviços. Os médicos deixaram pistas norteadoras sobre a dificuldade da consolidação da medicina científica no interior do território brasileiro. De modo que, as suas vivencias em Goiás revelam aspectos pouco conhecidos no que tange o exercício do oficio médico, como: desordens, hierarquias de poder, dificuldades no exercício do oficio, entre outros.

Com efeito, os três médicos compunham perfis distintos: Foggia chegou ao Brasil com o objetivo de fugir da polícia italiana; Moraes era membro de família abastada e não encontrou muitas dificuldades para angariar sucesso na carreira; Azeredo, por sua vez, enfrentou vários desafios de caráter financeiro para adquirir a tão almejada formação.

Segundo Magalhães, no território goiano, Foggia, Theodoro Rodrigues e Francisco Azeredo exerceram múltiplas funções para garantir o seu sustento, uma vez que o salário do médico era baixo ou em alguns casos devido ao reconhecimento intelectual

\footnotetext{
${ }^{6}$ Foggia nasceu em Mântua, capital da Lombardia, chegou ao Brasil no início da década de 1830.

${ }^{7}$ Moraes ingressou na Faculdade de Medicina do Rio de Janeiro no ano de 1835, aos 19 anos de idade, em 1840, apresentou a tese "O estrangulamento das hérnias enteroepiploicas e os meios de curar". Atuou como médico no Hospital São Pedro de Alcântara.

${ }^{8}$ Azeredo se consagrou na carreira de doutor durante a Guerra do Paraguai, quando ocupava o cargo de primeiro médico do Hospital Militar. Com o fim da guerra, retornou à cidade de Goiás, onde continuou praticando a medicina civil e militar e prestando serviços ao governo da província.
} 
e profissional mediante a comunidade. De forma geral, o elevado custo da consulta, que era inacessível a grande parte da população, reduzia assombrosamente a clientela. Assim, quando atendiam os desafortunados recebiam, na maioria das vezes, pagamento in natura, como, bacon, verduras, frutas, etc.

Os respectivos médicos também atuaram como professores do Liceu de Goiás, escola de nível secundário, criada no ano de 1846. Sendo assim, foram os principais transmissores dos princípios da medicina científica em Goiás ao longo do século XIX.

Destarte, por meio da leitura e análise da documentação vigente, percebe-se que a imagem de Goiás era ambígua, uma vez que ao mesmo tempo em que era parte do Império, estava à margem dele. Magalhães apontou os efeitos da alimentação na saúde dos goianos ao longo do século XIX, cujo tema é pouco explorado no Brasil. Dessa maneira, através das limitações da atividade de subsistência, havia um verdadeiro estado crônico de carestia e de crise alimentar que de forma constante se tornava fome declarada e generalizada.

A autora constatou que os goianos continuaram a ingerir alimentos com baixo teor nutritivo, cuja alimentação era baseada em milho, mandioca, arroz, feijão e carne seca, temperados com baixa quantidade de sal. No entanto, apesar de tal comida ter saciado a fome de muitos, em longo prazo contribuiu para a disseminação de doenças, principalmente no âmbito nutricional.

Deve-se suscitar e enfatizar que o processo de institucionalização da medicina em Goiás, também foi destacado na obra, época sobre a qual, se verificou um movimento pela definição dos espaços ocupados pelos que atuavam a serviço da saúde, em que a formação acadêmica passou a ser requisito obrigatório para a prática médica.

Portanto, caro leitor, a aventura pelos Males do Sertão é certamente, cheia de eventos importantes, tendo como pano de fundo o próprio sertão, que na maioria das vezes foi caracterizado como atrasado, inóspito, árido. E, de acordo com Magalhães, esse sertão pode ser interpretado como um centro de tradições e especificidades que é essencial para a compreensão da própria nação brasileira.

Através da análise socioeconômica e epidemiológica de Goiás no decorrer do século XIX, cujo ponto central é a relação entre alimentação e doenças, este livro se junta a outras pesquisas, perfazendo um debate historiográfico em torno da saúde e doenças em Goiás. Assim sendo, entre as inúmeras questões analisadas está o reduzido número de médicos e a forma como ocorre a sua inserção na sociedade. Isto é, um debate que se faz presente até em nossa contemporaneidade, pensando a história como processo e de forma 
não anacrônica. Contudo, a pesquisa desenvolvida por Magalhães traz uma efetiva contribuição historiográfica para o campo da saúde e das doenças e também para a história regional.

Fernanda Soares Rezende Mestre em História pela Universidade Federal de Goiás fernanda.soares.ufg@gmail.com

Henrique Martins da Silva

Doutorando em História pela Universidade Federal de Goiás henriquemartins.silva@yahoo.com.br

Resenha recebida em 1 de março de 2016.

Aprovada em 2 de abril de 2017.

DOI: $10.12957 /$ intellectus.2017.31660 